\title{
The Bermuda Oceanographical Station
}

\author{
By Prof. E. W. MacBride, F.R.S., Chairman of the Advisory \\ Committee of the Development Commission on Fishery Science
}

$\mathrm{T}$ HE British Government has decided to grant a sum of money in order to establish and carry on for a period of five years an oceanographical station in the Bermuda Islands. The management of the station has been vested in a Committee, of which I have the honour to be chairman, nominated by the Royal Society, and hence it seemed appropriate that I should endeavour to give to readers of NATURE an account of the reasons which led to the decision to found the station and the objects which it is hoped to attain by its activity.

At a time when taxation is so heavy in the United Kingdom, some members of the general public may think it a piece of quixotic extravagance to subsidize what might be regarded as a Colonial institution. The answer to this objection is that the station is not being established for the benefit of the Bermuda Islands but to help British fisheries.

At one time it was thought that by the artificial hatching of the eggs of our edible fish, and by then releasing the fry in the coastal waters, the fisherman's catch could be increased. Not so very long ago, haddock fry were thrown into the sea off the east coast of Scotland and herring fry were released in Loch Fyne, just as to-day lobster fry are poured into the sea near Barra Head in the Isle of Man. It was that brilliant zoologist and oceanographer Prof. Johan Hjört who first clearly showed the futility of this procedure. He pointed out that if one counted up the total number of fry hatched at one of the fishery stations and expressed this total in terms of the number of females necessary to produce them, the whole work of the station was equivalent to adding at enormous expense a few dozen female fish to the teeming millions already in the sea. The main service which fishery research can render to the fisherman is to tell him where to find his fish and what the magnitude of the catch in the coming season is likely to be.

In certain cases, however, the fishery expert can perform the additional service of proving that in some areas of the narrow seas, such as the Flemish Bight, too heavy a toll is being levied on the young fish and that the remedy for this is to make it illegal to sell fish below a certain size, and to insist on the nets used having a certain width of mesh so that the smaller fish can escape through them.

Prof. Johan Hjört was perhaps the first to pre- dict successfully the future yield of edible fish and to find spawning grounds off the coast of Norway hitherto unknown. All honour should be given to him for leading the way; but as he would be the first to admit, the conditions of the North Atlantic near the coast of Norway are simple compared to those obtaining in the North Sea, in the English Channel and in the Western Atlantic where it bathes our shores. Nevertheless, by hard continuous labour and the piling up of innumerable data, which constitute the only road to success in zoological science, the fishery experts of the Scottish Fishery Board and those of our own Ministry of Fisheries, under the guidance of the chief scientific adviser, Dr. E. S. Russell, have succeeded in predicting the yield of the haddock fishery in Scotland and of the herring fishery off the East Anglian coast, in each case about six months ahead. In other areas, baffling and hitherto unsolved problems confront them. One small example of these problems may be given.

For many years, Mr. E. Ford, now vice-director of the Plymouth Marine Biological Station, has been investigating the herring fishery in the southwest area of the English Channel. He has found that during the past five or six years there has been a steady decline in the yield of this fishery and that this decline has been due to the fact that the fishermen have been drawing on the same stock of fish, which every year has been growing older and fewer in numbers. Far too few herring fry are entering the Channel to replace the losses in the older fish. The cause which Mr. Ford has found for this deficiency is the falling off in the stream of highly saline Atlantic water entering the Channel. This water is rich in phosphates and supports a large number of micro-organisms on which the fry feed. Mr. Ford has strong suspicions that the fry which should have entered the Channel are to be found farther afield; and that the fishery which the men of Devon and Cornwall exploited is now to be sought for off the south coast of Treland.

This brings us to the central problem of British fishery research, namely, the cause of the periodic variation in the pulse of warm Atlantic waterpopularly known as the Gulf Stream, though the actual Gulf Stream cannot be distinguished east of Newfoundland-which washes our shores. If we could solve that problem, we should be able to 
give our fishermen a guidance out of all proportion greater than that which has been so far afforded to them. The so-called Gulf Stream, as is well known, travels in a north-east direction from the coast of Florida and pours through the Faeroe Channel, north of the Shetlands, into the North Sea. Strange to say, the stream, when strong, does not bring with it an abundant fishery but the reverse. Our most valuable food-fish loathe it like poison. Poor catches of herring, haddock, plaice and sole go along with a strong Gulf Stream. This stream brings with it enormous numbers of jelly-fish of all kinds and of gelatinous algæ which are avoided water freshly pumped up was continuously passing. The bolting silk was afterwards rinsed in a bottle of formalin. After a few minutes passage of Labrador water, the contents of the bottle resembled a thick opaque emulsion, whereas after several hours passage of Gulf Stream water only a few grains were found in the bottle. The Labrador Current varies in width and when it invades the territory of the Gulf Stream it causes the death of the fish which live in the warmer water. On one notable occasion the 'file-fish' (Lopholatilus), which is allied to our sea-bass and is prized as a food-fish in America, was found floating dead in

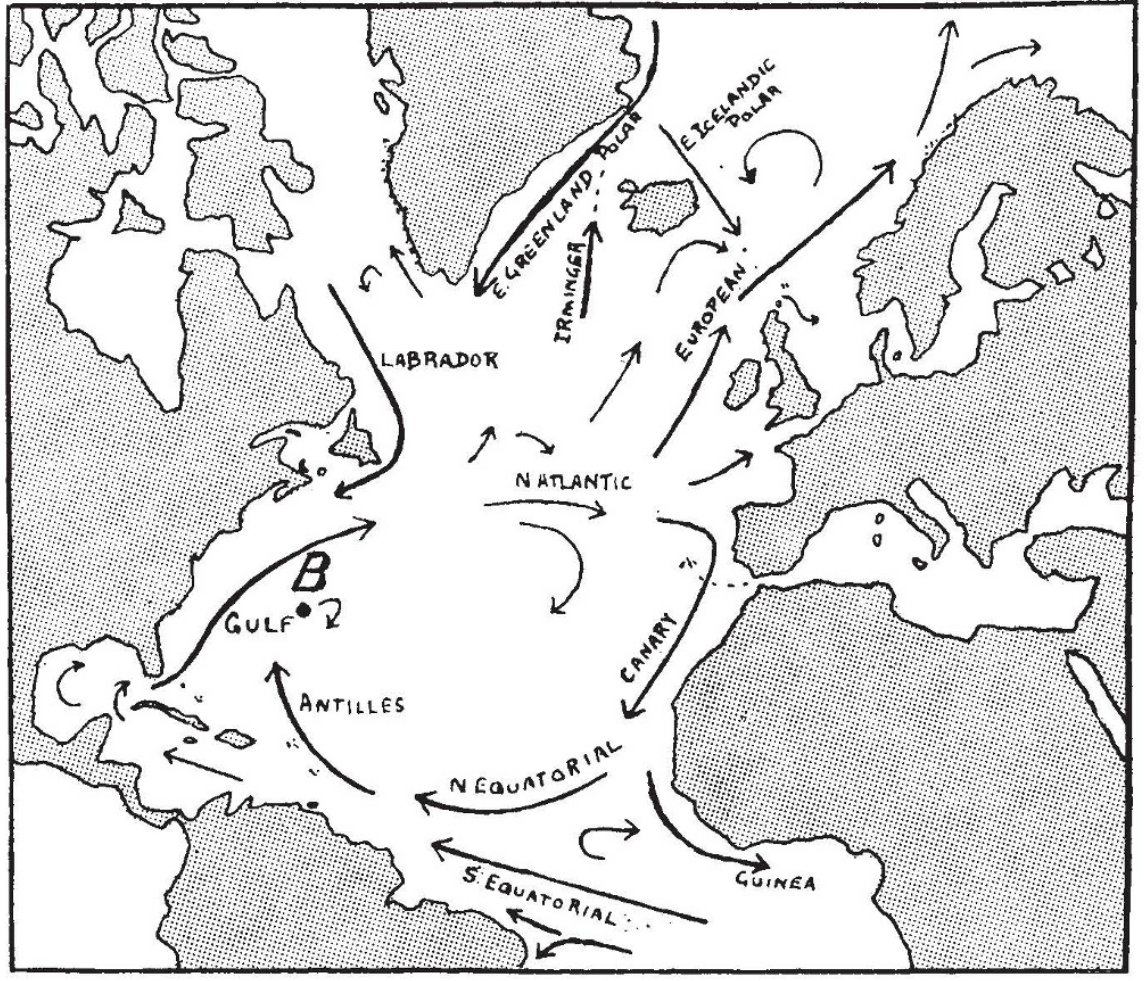

Fig. 1.

The princtpal Atlantic currents. $B=$ Bermuda

by our fish. The cold current which streams down the coast of Norway-unlike the Channel wateris very rich in phosphates and gives support to an enormous multitude of minute Crustacea on which herring, haddock and plaice feed.

As most people are aware, a similar current, known as the Labrador Current, flows down the eastern shores of North America as far as Cape Hatteras, where it dives under the Gulf Stream. Its temperature is very low (in the neighbourhood of $40^{\circ} \mathrm{F}$.) and yet it is teeming with life. On one occasion Prof. W. Garstang when crossing the Atlantic eastwards tested the relative abundance of life in the Gulf Stream and Labrador Currents respectively by attaching a piece of bolting cloth to the bath tap of the steamer through which sea- millions at the surface of the water. The passage from Gulf Stream to Labrador Current is a dramatic experience-which has happened to me on several occasions. Leaving the north of Ireland in the early autumn, one encounters the familiar type of mild stormy weather accompanied by drizzling rain, so unhappily associated with Irish summers. The bath water was exceedingly mild, as indeed is the sea-water encountered in bathing off the Irish coast in September. In a few hours the whole aspect of the sky changed. The weather might become dazzlingly clear or grey and foggy. The temperature fell and the bath-water became icy.

We have used for the warm water the term "so-called Gulf Stream" advisedly. The term 'Gulf Stream' in the narrower sense means the 
water issuing from the Gulf of Mexico. But as a glance at the map (Fig. 1) will show, this current is joined by another termed the Antillean-which is fed by two currents, the North Equatorial and the South Equatorial, running west from the coast of Africa, and the water flowing through the Straits of Florida forms only one fifth of the total volume of the warm current. When this water reaches the coast of Africa, part of it turns south as the Canary Current which eventually joins the North Equatorial Current, so that it will be seen that in this way a huge vortex is constituted in the centre of which lies the calm water of the Sargasso Sea.

It is the merit of Prof. Garstang, who is a member of the Advisory Committee of the Development Commission on fishery matters, and of Dr. Robert Gurney who is a relative of the former Governor of Bermuda, to have brought before the notice of the Development Commission the suitability of the Bermuda Islands as a base for oceanographical research. The term 'islands' as applied to Bermuda is misleading. The gaps between the separate islands are so shallow that they are astually spanned by railway bridges, and the islands themselves are formed of nothing but wind-blown fragments of coral and other calcareous organisms cemented together by the deposit left by evaporating rain. It is clear that we have here the remains of a typical atoll without any trace of the peak which presumably once occupied the centre of the lagoon. Fifty miles north or south of Bermuda the enormous depth of 2,500 fathoms is reached, and Prof. Garstang has compared Bermuda to a lightship permanently moored in the centre of the ocean.

Turning again to the map, it will be seen that Bermuda $(B)$ lies about 100 miles east of the Gulf Stream. Opposite it, west of the Stream on the coast of Massachusetts, is situated the Woods Hole Oceanographical Station, not to be confounded with the Woods Hole Biological Station, which is a totally distinct institution. The scheme of research planned by the Bermuda Committee is one to be carried out in the closest and most friendly co-operation with the Woods Hole Oceanographical Institute. The American corporation has a suitable research steamer, and the Bermuda Committee has appointed a sub-committee to draft plans for buying or building a suitable motor-boat. It is arranged that the two boats at suitable intervals shall penetrate about 100 miles into their respective sides of the Gulf Stream and take observations on the temperature and salinity at various depths. From these observations it can be shown that by an easy mathematical calculation the volume and velocity of the Gulf Stream can be computed and therefore the variation in volume over a series of years can be ascertained. In five years' time it is confidently anticipated that the correlation between these variations and the fluctuations in British fisheries will begin to emerge from obscurity, and the justification for continuing the research will become obvious.

As most people are aware, a Bermuda biological station has been in existence for about forty years. This is controlled by a Board of Governors of which until quite recently Prof. E. G. Conklin, of Princeton, the very distinguished American embryologist, was chairman. This corporation has in recent years endeavoured to widen its appeal by including in its number Dr. E. J. Allen, former director of the Marine Biological Association's laboratories at Plymouth, and the late Prof. J. H. Ashworth, of Edinburgh, and by appointing an Englishman, Dr. J. F. G. Wheeler, late of the Discovery Expedition, as director.

The investigations carried out at this station have been concerned solely with the fauna and flora of the warm water of the lagoon, as no boat was available which could safely be trusted in the turbulent oceanic water outside. The Bermuda Committee has entered into negotiations with the governors of the Bermuda station, and have been met in the most friendly spirit by that corporation. The Bermuda Committee has arranged to pay $£ 250$ a year for the rent of a portion of the Bermuda Biological Laboratory, including, of course, its equipment in tanks and water-supply. In addition, the Committee has agreed to pay half Dr. Wheeler's salary, as he, by his experience with the Discovery and by his local knowledge, is obviously the most suitable man to become director of the new Oceanographical Institute. The work of the Bermuda station is very intermittent and it is computed that he will be able to allot at least half his time to the Oceanographical Institute, and that indeed this work will extend the opportunities of ordinary biological workers at Bermuda, who may thus gain some acquaintance with the oceanic fauna.

The decision of the Government to support the Bermuda scheme was arrived at only on December 24 of last year and was immediately communicated by cable to the Bermuda corporation. The money is to be furnished in the first instance from the funds of the Ministry of Fisheries and thereafter by the Development Commission. As the whole scheme originated with the Commission, it may seem strange that the Commission did not at once assume the management of it. But the Commission was advised that its function was to criticize schemes put before it, not to initiate them, and the Royal Society was asked to nominate a committee to manage the new Institute. Of this Committee, Dr. Stanley Kemp, formerly leader of the Discovery Expedition, now one of its governors, 
and the new director of the Marine Biological Station at Plymouth, is secretary. The Committee met about two months ago and considered the grant of money necessary to carry out its plans; it applied for this grant to the Development Commission, which unanimously approved it. It then became possible to co-opt to the Committee two distinguished civil servants, namely, Mr. H. G. Maurice, assistant secretary of the Ministry of Agriculture and Fisheries, and Dr. E. S. Russell, chief scientific adviser on fishery matters. Needless to say, the assistance of these two members will be an invaluable addition to the powers of the Committee.
The staff to be appointed consists of Dr. Wheeler as director, a hydrologist, who will proceed to Woods Hole to be trained in the mathematical methods employed by that institute, and a director's assistant, who will be a naturalist.

It is perhaps vain to endeavour to lift the veil which shrouds the future, but it is to be remembered that the research work at Plymouth is really mainly oceanographical in character and with prophetic vision Dr. Kemp looks forward to the time when the Plymouth research will extend into mid-Atlantic and there meet in cordial co-operation with an eastward extension of the work of the Bermuda station.

\section{Conduction of Electricity in Solids*}

\section{By Prof. N. F. Mott, F.R.S.}

$\mathrm{T}^{\mathrm{H}}$ HE modern theory of the conduction of electricity in solids has already been applied to a large number of special problems; all that can be attempted here is a broad sketch of the fundamental ideas of the theory, together with an account of one or two of the most recent developments.

In the classical Drude theory, the conductivity of a metal depends on three quantities; namely, $N$, the number of free electrons per unit volume of the metal; $v$, their mean velocity, and $l$, their mean free path. Elementary considerations then give for the conductivity, $\sigma$,

$$
\sigma=\frac{1}{2} N e^{2} l / m v
$$

With certain slight modifications (in the quantum mechanical treatment $v$ is actually the maximum electronic velocity) this formula may be transferred to the quantum mechanical treatment; the new theories are, however, important when we come to estimate $N, l$ and $v$.

In monovalent metals we should expect that each atom would contribute just one to the total number of free electrons, so that $N$ will be equal to the number of atoms per unit volume. For the alkali metals there is direct experimental evidence that this is the case. R. W. Wood ${ }^{1}$ has shown that thin films of these metals deposited on glass are transparent to ultra-violet radiation below a certain wave-length, the transition from the opaque to the transparent region being rather sharp. Now as Zener ${ }^{2}$ was the first to point out, one can apply to the reflection of light from a metal, provided that the absorption is neglected, the same formula as that used in the theory of

* Substance of a course of lectures delivered at the Royal Institution on January 19, 26 and February 2. the reflection of wireless waves from the upper atmosphere, namely,

$$
n^{2}=1-N e^{2} / \pi m v^{2}
$$

where $n$ is the refractive index and $\nu$ the frequency of the radiation. $n$ is real only for short wavelengths ; for long wave-lengths the right-hand side of (2) is negative and $n$ imaginary, so that total reflection of the radiation takes place. From the observed long wave-length limit of the transparent region, therefore, $N$ can be determined; it turns out to be quite near to the number of atoms per unit volume for each of the alkali metals. Formula (2) cannot be applied to other metals owing to the existence of characteristic absorption bands, such as the band at $3100 \mathrm{~A}$. in silver.

As regards the mean velocity $v$ of the metallic electrons, classical statistics, treating the electrons as a perfect gas, demand that their mean kinetic energy shall be $3 k T / 2$, corresponding to a velocity of $1.2 \times 10^{7} \mathrm{~cm} . / \mathrm{sec}$. at room temperature. The application of Fermi-Dirac statistics, first made to this problem by Sommerfeld ${ }^{3}$, leads to the conclusion that the mean velocity has a very much greater value. The general ideas of the FermiDirac statistics are most clearly seen by considering an idealized 'one-dimensional' metal, consisting of electrons free to move up and down a line of length $L$. We neglect first the interaction of the electrons, both with one another and with the atoms of the lattice. Now the velocity $v$ of an electron is connected with its de Broglie wavelength $\lambda$ by the well-known formula

$$
\lambda=:=h / m v \text {. }
$$

For an electron confined within a metal of length $L$, the de Broglie wave associated with the electron 